\title{
Evaluation on external economies of renewable energy resource utilization: Taken wind power engineering project as example
}

\author{
Yanlin $Q u^{1, *}$, Yilan $\mathrm{Su}^{2}$ \\ ${ }^{1}$ Business College of Honghe University, Mengzi County, Yunnan Province, 661100, China \\ ${ }^{2}$ College of Life Science and Technology, Honghe University, Mengzi County, Yunnan Province, 661100, China
}

\author{
Email address: \\ yanlinqu@gmail.com (Yanlin Qu)
}

\section{To cite this article:}

Yanlin Qu, Yilan Su. Evaluation on External Economies of Renewable Energy Resource Utilization: Taken Wind Power Engineering Project as Example. Science Journal of Energy Engineering. Special Issue: Soft Computing Techniques for Energy Engineering.

Vol. 3, No. 4-1, 2015, pp. 1-5. doi: 10.11648/j.sjee.s.2015030401.11

\begin{abstract}
Different wind power projects have different external economics level, the practical evaluation on which can provide reference for wind power projects selection and qualify the role of completed projects. In this paper, the external economies of wind power engineering projects were evaluated by employing VIKOR method. The basic theory of VIKOR method was firstly introduced, and then the empirical evaluation was performed. After the evaluation index system was built from environmental, social and economic aspects, the external economies of three selected wind power engineering projects in Hebei province were studied. The evaluation result shows the external economies of wind power project \#3 are the best one. The application of VIKOR method in external economies evaluation of wind power project is effective and feasible.
\end{abstract}

Keywords: Wind Power Engineering Project, External Economies Evaluation, VIKOR Method

\section{Introduction}

Renewable resources are a part of Earth's natural environment and the largest components of its ecosphere, which is an organic natural resource that can replenish in due time compared to the usage, either through biological reproduction or other naturally recurring processes [1]. Renewable energy resources are a kind of energy resources, which have the characteristics of cyclic regeneration and sustainable utilization. Renewable energy resources include wind energy, solar energy, biomass energy, and so on. With the development of human society, the important role of energy in people's daily lives is becoming increasingly prominent. Nowadays, the energy supply shortage and environmental pollution issues make exploiting and utilizing renewable energy as the focus of worldwide concerns [2, 3]. Energy solutions for the future will increasingly depend on the use of renewable energy resources.

In the past many years, China's wind power has developed rapidly, the cumulative installed capacity of which has increased from $0.3 \mathrm{GW}$ in 2000 to $77 \mathrm{GW}$ in 2013. In 2010, China surpassed the United States and ranked the first in terms of cumulative installed capacity of wind power [4]. As a kind of renewable energy, wind energy has the advantages of huge reserves, widely distribution, renewable and pollution-free [5]. External economies are benefits that are created when an activity is conducted by a company or other type of entity, with those benefits enjoyed by others who are not connected with that entity [3]. The entity that is actually managing the activity does not receive the external economies, although the creation of these benefits for outsiders usually has no negative impact on that entity [6]. The benefits produced by wind power, such as environmental emission reduction and economic growth, can enjoys by outsiders, such as the residents, nation, and ecology. Therefore, wind power has external economics.

Currently, the study on external economies mainly focuses on the industry and trade. Ref. [7] estimated the indexes internal returns to scale and external economies for two-digit manufacturing industries in West Germany, France, the U.K., and Belgium countries; Ref. [8] reviewed the international trade literature on intra-industrial and inter-industrial production externalities; Ref. [9] proposed a two-country model of monopolistic competition in which differentiated 
products are produced subject to external economies of scale and two countries differ only in size measured by the factor endowment; Ref. [10] studied the impact on productivity growth of technological externalities, both inter- and intra-industry, national or international, at the industry level for the EU countries and the period 1995-2002.

This paper focuses on the external economies of wind power project, and employs the VIKOR method to evaluate the external economies of wind power project. The VIKOR method is a multi-criteria decision making (MCDM) method, which was originally developed by Serafim Opricovic [11]. As a MCDM method, VIKOR has been applied in many issues, such as supplier selection [12], water resources planning [13], service quality of airports [14], and so on.

This paper comprises the following: Section 2 introduces the basic theory regarding VIKOR method; taking three wind power engineering projects in Hubei province as example, the external economies evaluation of wind power engineering projects based on VIKOR model is performed in Section 3; Section 4 concludes this paper.

\section{Basic Theory of VIKOR Method}

VIKOR method is a MCDM method to solve decision problems with conflicting and non-commensurable criteria, assuming that compromise is acceptable for conflict resolution, the decision maker wants a solution that is the closest to the ideal, and the alternatives are evaluated according to all established criteria. VIKOR ranks alternatives and determines the solution named compromise that is the closest to the ideal [15].

Suppose the set of $\mathrm{m}$ feasible alternatives be $X=\left\{X_{1}, X_{2}, \cdots, X_{m}\right\}$, the set of $\mathrm{n}$ criterion functions be $O=\left\{O_{1}, O_{2}, \cdots, O_{n}\right\}$. The input data are the elements $a_{i j}$ of the performance matrix $A=\left\{a_{i j}\right\}_{m \times n}$, where $a_{i j}$ is the value of the $\mathrm{j}$-th criterion function for the alternative $X_{i}$.

The basic step of VIKOR method is as follows.

\subsection{Determine the Criterion Weight}

The criterion weight determination is very important, which has great impact on the evaluation result. There are many criterion weight determination methods, such as expert consultation method, AHP method, entropy weight method, and so on.

\subsection{Normalize the Performance Matrix}

Normalize the initial performance matrix $A=\left\{a_{i j}\right\}_{m \times n}$ to the standardized decision matrix $R=\left\{r_{i j}\right\}_{m \times n}$ according to Eq. (1).

$$
r_{i j}=\left\{\begin{array}{l}
\frac{a_{i j}-\min _{i}\left(a_{i j}\right)}{\max _{i}\left(a_{i j}\right)-\min _{i}\left(a_{i j}\right)}, i \in I_{1}, j \in N \\
\frac{\max _{i}\left(a_{i j}\right)-a_{i j}}{\max _{i}\left(a_{i j}\right)-\min _{i}\left(a_{i j}\right)}, i \in I_{2}, j \in N
\end{array}\right.
$$

where $I_{1}$ and $I_{2}$ represent the subscript set of benefit-type criterion and cost-type criterion, respectively; $N=\{1,2, \cdots, n\}$.

\subsection{Determine the Positive and Negative Ideal Solution}

The positive ideal solution is

$$
r^{*}=\left\{r_{1}^{*}, r_{2}^{*}, \cdots, r_{n}^{*}\right\}=\max _{i}\left\{r_{i j}, j=1,2, \cdots, n\right\}
$$

The negative ideal solution is

$$
r^{-}=\left\{r_{1}^{-}, r_{2}^{-}, \cdots, r_{n}^{-}\right\}=\min _{i}\left\{r_{i j}, j=1,2, \cdots, n\right\}
$$

\subsection{Calculate the Group Utility Value and Individual Regret Value}

The group utility value can be calculated according to Eq. (4), and the individual regret value can be calculated according to Eq. (5).

$$
\begin{gathered}
S_{i}=\sum_{j} w_{j} \frac{r_{j}^{*}-r_{i j}}{r_{j}^{*}-r_{j}^{-}} \\
R_{i}=\max \left\{w_{j} \frac{r_{j}^{*}-r_{i j}}{r_{j}^{*}-r_{j}^{-}}, j \in N\right\}
\end{gathered}
$$

\subsection{Calculate the Comprehensive Ranking Index}

The comprehensive ranking index can be calculated according to Eq. (6).

$$
Q_{i}=v \frac{S_{i}-S^{*}}{S^{-}-S^{*}}+(1-v) \frac{R_{i}-R^{*}}{R^{-}-R^{*}}
$$

where

$$
\begin{aligned}
S^{*} & =\min _{i} S_{i} \\
S^{-} & =\max _{i} S_{i} \\
R^{*} & =\min _{i} R_{i} \\
R^{-} & =\max _{i} R_{i}
\end{aligned}
$$

$v$ is introduced as a weight for the strategy of maximum group utility, $v \in[0,1] ; 1-v$ is the weight of the individual regret. In VIKOR method, the value of $\mathrm{v}$ is usually set as 0.5 , which indicates the decision making is performed based on 
the balanced compromising way.

Therefore, the decision making can be made according to the value of $Q_{i}$. The alternative with the minimum $\mathrm{Q}$ value is the best one. The calculation process of VIKOR method for evaluation is shown in Fig. 1.

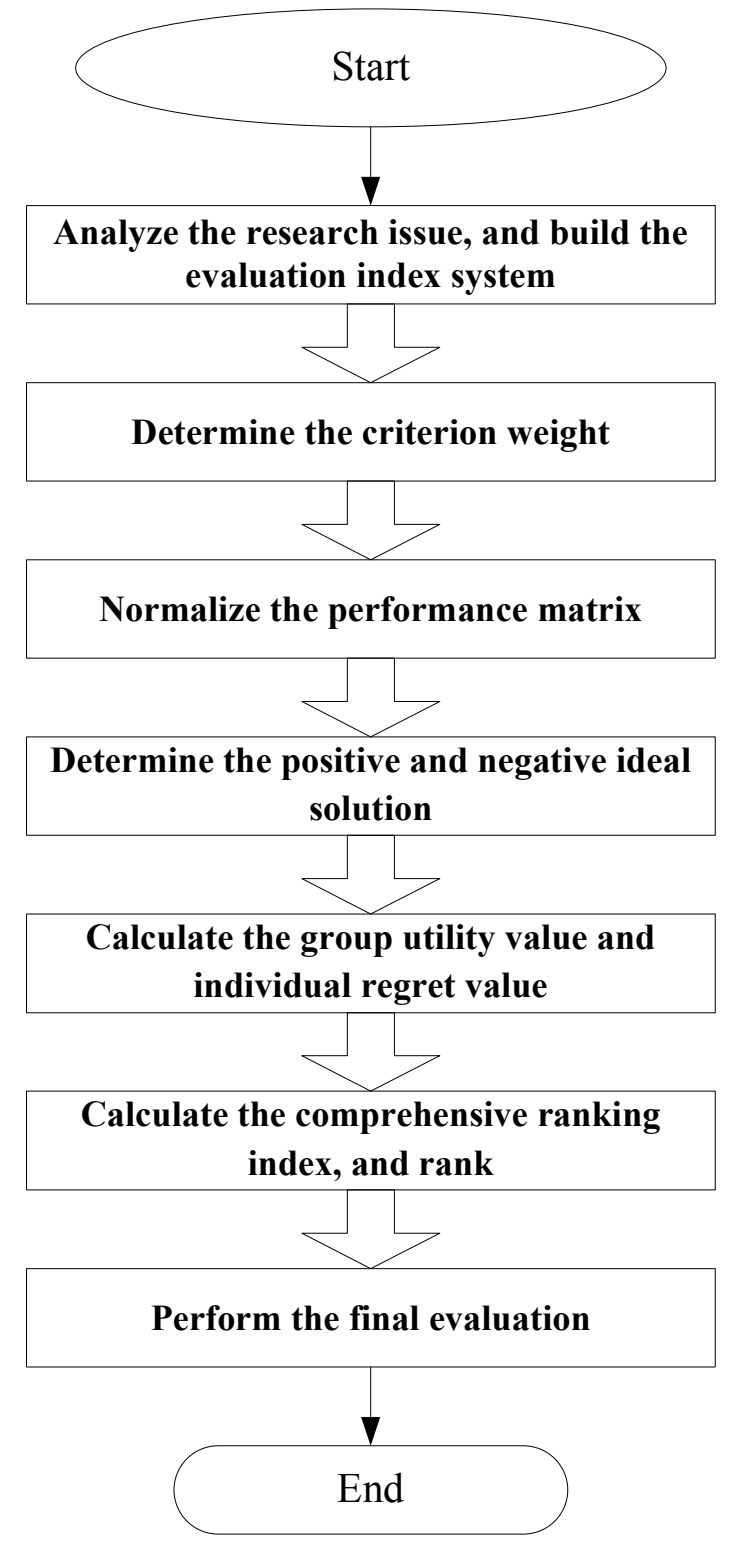

Figure 1. The calculation process of VIKOR method.

\section{Empirical Evaluation}

The wind resource is abundant in Hebei province. In 2013, the cumulative on-grid installed capacity of wind power amounted to $7.75 \mathrm{GW}$ in Hebei province, which ranks the second in China. In the past few years, there are several approved wind power engineering projects, such as GUOHUA KUYUANBAYUAN wind farm. Therefore, three wind power engineering projects in Hebei province were selected in this paper.
Firstly, the evaluation index system of external economies of wind power engineering project was built, and then an evaluation on the external economies of wind power engineering projects was carried out by employing VIKOR model.

\subsection{Build the Evaluation Index System}

When building the evaluation index system, two methods are adopted, namely Questionnaire and Literature review. After reviewing the relative literatures, the Questionnaire was designed. Questionnaires about the external economies of wind power engineering project were dispatched to experts and engineers in the field of wind power. The external economies evaluation index system was obtained by analyzing the results of questionnaires, the result of which is shown in Fig.2. The external economies of wind power engineering project are divided into environmental benefit, social benefit, and economic benefit. All of the indices are the greatest-type index.

\subsection{Evaluation Process}

(1) Determine the criterion weight

In this paper, the expert consultation method was employed to determine the criterion weight. 50 criterion weight scoring tables are distributed to university professors, enterprise expertise and engineers. According to the statistic results, the criterions weights of external economies of wind power engineering project are determined, which are listed in Table 1.

(2) Normalize the performance matrix

The external economies criterions scoring of three wind power wind power engineering projects are listed in Table 2.

So, we can obtained the performance matrix $A=\left\{a_{i j}\right\}_{m \times n}$ :

$$
A=\left[\begin{array}{cccccccc}
6.7 \% & 23.3 \% & 11 \% & 7 \% & 3.8 \% & 2 \% & 43 \% & 34 \% \\
8.9 \% & 19.8 \% & 10.5 \% & 6 \% & 4.4 \% & 1.3 \% & 46 \% & 52 \% \\
7.7 \% & 20.9 \% & 14 \% & 5 \% & 4.3 \% & 1.7 \% & 47 \% & 46 \%
\end{array}\right]
$$

According to Eq. (1), the standardized decision matrix $R=\left\{r_{i j}\right\}_{m \times n}$ can be obtained:

$$
R=\left[\begin{array}{cccccccc}
0 & 1 & 0.14 & 1 & 0 & 1 & 0 & 0 \\
1 & 0 & 0 & 0.5 & 1 & 0 & 0.75 & 1 \\
0.45 & 0.31 & 1 & 0 & 0.83 & 0.57 & 1 & 0.67
\end{array}\right]
$$

(3) Determine the positive and negative ideal solution According to Eq. (2), the positive ideal solution can be obtained, which is $r^{*}=\{1,1,1,1,1,1,1,1\}$, and the negative ideal solution is $r^{-}=\{0,0,0,0,0,0,0,0\}$. 


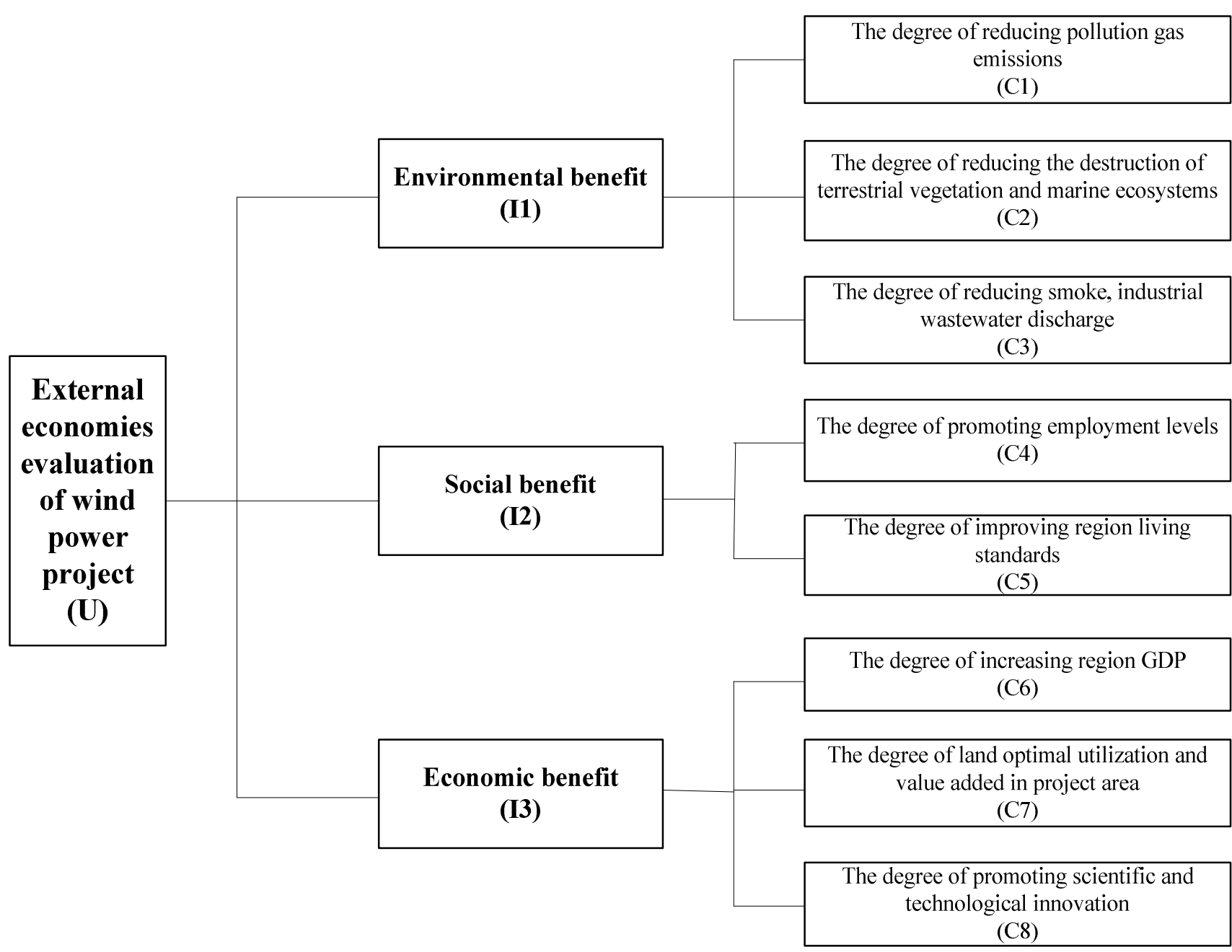

Figure 2. External economies evaluation index system of wind power engineering project.

Table 1. Weights of external economies evaluation criterions

\begin{tabular}{|c|c|c|c|c|c|c|c|c|}
\hline Criterion & C1 & $\mathrm{C2}$ & C3 & $\mathrm{C} 4$ & C5 & C6 & C7 & C8 \\
\hline Weight & 0.21 & 0.11 & 0.13 & 0.14 & 0.08 & 0.17 & 0.07 & 0.09 \\
\hline
\end{tabular}

Table 2. Criterion values of three wind power projects

\begin{tabular}{|c|c|c|c|c|c|c|c|c|}
\hline $\begin{array}{ll}\text { Scoring } & \text { Criterion } \\
\end{array}$ & $\mathrm{C} 1$ & $\mathrm{C2}$ & C3 & $\mathrm{C} 4$ & C5 & C6 & C7 & C8 \\
\hline Wind power project \#1 & $6.7 \%$ & $23.3 \%$ & $11 \%$ & $7 \%$ & $3.8 \%$ & $2 \%$ & $43 \%$ & $34 \%$ \\
\hline Wind power project \#2 & $8.9 \%$ & $19.8 \%$ & 10.5 & $6 \%$ & $4.4 \%$ & $1.3 \%$ & $46 \%$ & $52 \%$ \\
\hline Wind power project \#3 & $7.7 \%$ & $20.9 \%$ & $14 \%$ & $5 \%$ & $4.3 \%$ & $1.7 \%$ & $47 \%$ & $46 \%$ \\
\hline
\end{tabular}

(4) Calculate the group utility value and individual regret value

According to Eq. (4), the group utility value of three wind power projects can be calculated, which are

$$
S_{1}=0.5614 ; S_{2}=0.4975 ; S_{3}=0.4462
$$

According to Eq. (5), the individual regret values of three wind power projects can be calculated, which are

$$
R_{1}=0.21 ; R_{2}=0.17 ; R_{3}=0.14
$$

(5) Calculate the comprehensive ranking index
According to Eq. (6), set $\mathrm{v}=0.5$, the comprehensive ranking index of three wind power projects can be calculated, which are

$$
Q_{1}=1 ; Q_{2}=0.437 ; Q_{3}=0
$$

Therefore,

$$
Q_{3}<Q_{2}<Q_{1} \Rightarrow Q_{3} \succ Q_{2} \succ Q_{1}
$$

According to the calculation result, we can safely draw the conclusion that the external economies of wind power project $\# 3$ are the best one. 


\section{Conclusions}

As a kind of renewable energy resource utilization, wind power engineering projects have developed rapidly in China in the past years. Different wind power projects have different external economics level, the practical evaluation on which can provide reference for wind power projects selection. In this paper, the external economies of three wind power engineering projects are evaluated based on the VIKOR method. After the evaluation index system was built, the weights firstly were determined, and then the evaluation was performed. The calculation result shows the external economies of wind power project \#3 are the best one, which indicates the construction of wind power project \#3 plays greater role in the promotion of environmental, social and economic development.

\section{Acknowledgements}

The author thanks editor and reviewers for their comments and suggestions.

\section{References}

[1] http://en.wikipedia.org/wiki/Renewable_resource

[2] Tükenmez M, Demireli E. Renewable energy policy in Turkey with the new legal regulations [J]. Renewable Energy, 2012, 39(1): 1-9.

[3] Li H, Guo S. External economies evaluation of wind power engineering project based on analytic hierarchy process and matter-element extension model [J]. Mathematical Problems in Engineering, 2013, 2013.

[4] Zhang S, Andrews-Speed P, Zhao X. Political and institutional analysis of the successes and failures of China's wind power policy [J]. Energy Policy, 2013, 56: 331-340.
[5] Chingulpitak S, Wongwises S. Critical review of the current status of wind energy in Thailand [J]. Renewable and Sustainable Energy Reviews, 2014, 31: 312-318.

[6] J. Markusen. Micro-foundation of external economies [J]. Canadian Journal of Economics, 1990, 23(1): 495-508.

[7] Caballero R J, Lyons R K. Internal versus external economies in European industry[J]. European Economic Review, 1990, 34(4): 805-826.

[8] Choi J Y, Yu E S H. External economies in the international trade theory: a survey[J]. Review of International Economics, 2002, 10(4): 708-728.

[9] Suga N. A monopolistic-competition model of international trade with external economies of scale[J]. The North American Journal of Economics and Finance, 2007, 18(1): 77-91.

[10] Claver N D, Castejón C F, Gracia F S. External economies as a mechanism of agglomeration in EU manufacturing[J]. Applied Economics, 2012, 44(34): 4421-4438.

[11] Opricovic S, Tzeng G H. Extended VIKOR method in comparison with outranking methods [J]. European Journal of Operational Research, 2007, 178(2): 514-529.

[12] Sanayei A, Farid Mousavi S, Yazdankhah A. Group decision making process for supplier selection with VIKOR under fuzzy environment[J]. Expert Systems with Applications, 2010, 37(1): 24-30.

[13] Opricovic S. Fuzzy VIKOR with an application to water resources planning[J]. Expert Systems with Applications, 2011, 38(10): 12983-12990.

[14] Kuo M S, Liang G S. Combining VIKOR with GRA techniques to evaluate service quality of airports under fuzzy environment [J]. Expert Systems with Applications, 2011, 38(3): 1304-1312.

[15] http://en.wikipedia.org/wiki/VIKOR_method 